\title{
Summary of New Lessons: The Power of Educating Adolescent Girls
}

Cynthia B. Lloyd

Population Council

Follow this and additional works at: https://knowledgecommons.popcouncil.org/departments_sbsr-pgy

Part of the Demography, Population, and Ecology Commons, Education Commons, Family, Life Course, and Society Commons, Gender and Sexuality Commons, International Public Health Commons, and the Medicine and Health Commons

How does access to this work benefit you? Let us know!

\section{Recommended Citation}

Lloyd, Cynthia B. 2011. "Summary of New Lessons: The Power of Educating Adolescent Girls," Promoting Healthy, Safe, and Productive Transitions to Adulthood Brief no. 33. New York: Population Council.

This Brief is brought to you for free and open access by the Population Council. 


\title{
Summary of New Lessons: The Power of Educating Adolescent Girls
}

\author{
Prepared by Cynthia B. Lloyd
}

O ver the past 15 years, girls' education in the developing world has been a story of progress. Interest and financial backing from the development community have grown steadily in response to accumulating evidence documenting the many benefits of girls' schooling, and female education is now a major part of global development commitments, including the Millennium Development Goals.

Alongside this global interest, school enrollments have climbed.

The large majority of girls now attend primary schools, and most girls attend school into early adolescence. While primary schooling is a basic need for all children, education for adolescents can be transformative. Many benefits are immediate. The prospect of secondary education motivates girls to complete primary school. Being in school along with boys during adolescence fosters greater gender equality in the daily lives of adolescents. Education for adolescent girls helps them avoid long working hours and early pregnancies, and lowers their risk of HIVI AIDS. In the long term, secondary education offers greater prospects of remunerative employment, with girls receiving substantially higher returns in the workplace than boys when both complete secondary school.

Evidence on girls' education indicates that the gender gap is closing, and higher enrollments are boosting economic returns. But there is still a long way to go. According to a 2008 UN report, 113 countries failed to reach the 2005 Millennium Development Goals on gender equality in education. In Africa, girls' secondary school enrollments have fallen relative to boys' since 2000 . And throughout the developing world, young women are underrepresented in the workforce (United Nations 2008).

\section{Research on girls' schooling}

The Population Council's research on schooling seeks to foster a deeper understanding of the patterns and trends in schooling for girls and more particularly the relationship between experiences in school, school quality, and various adolescent outcomes, including: school attendance and attainment; time use and work roles; sexual and repro-
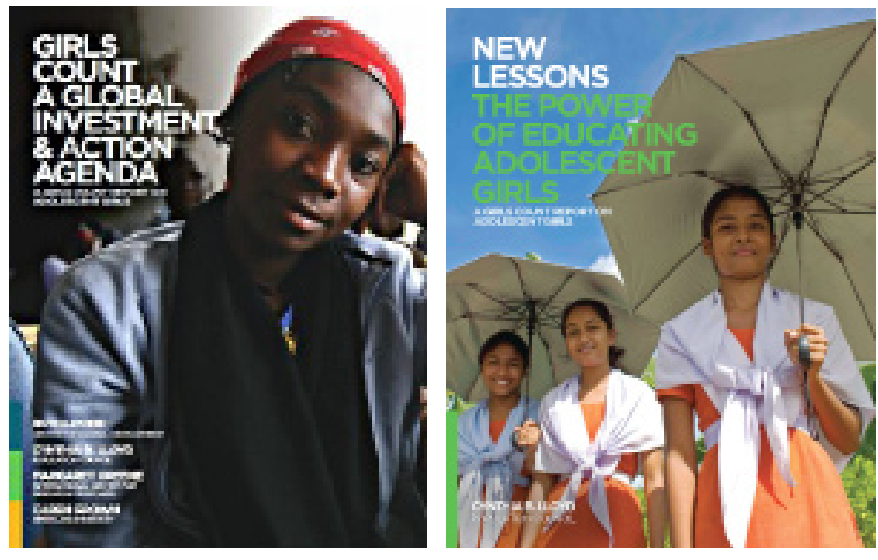

ductive health; gender role attitudes, citizenship and community participation; and transitions to marriage and childbearing. In 2008, the Council contributed to a global call for investment in girls living in the poorest countries and communities through a report entitled Girls Count: $A$ Global Investment and Action Agenda (Levine et al. 2008). Levine, Lloyd, Greene, and Grown made the case for investing in girls and outlined actions that policymakers, donors, the private sector, and development professionals can and should take to improve the prospects for girls' wellbeing in the developing world. The agenda includes actions to count girls with better data in order to make them more visible, to invest in girls in strategic areas of need, and to provide them with a fair share of resources and opportunities. These recommendations were informed by rich evidence of the many social and economic benefits that are directly or indirectly tied to girls' welfare and were designed to break the cycle of past neglect. Within each recommended arena of action, educational investments feature prominently. A Global Investment and Action Agenda, commissioned by the United Nations Foundation and the Nike Foundation, was the foundation on which a new Girls Count series was produced. The series authors have continued beyond this groundbreaking work to explore girls' lives further. 
Findings from the Council's most recent work on girls' education, and our latest contribution to the Girls Count series are outlined in New Lessons: The Power of Educating Adolescent Girls written by Cynthia B. Lloyd with Juliet Young. In this report, the authors demonstrate that education for girls during adolescence can be transformative, and identify a broad array of promising educational approaches, which should be evaluated for their impact. Given the lack of information on education programs for girls, the report provides new data and analysis from research on more than 300 past and current programs and projects. It offers evidence on how proven practices, including scholarships for girls and the recruitment and training of female teachers, can increase the number of adolescent girls attending school and highlights the pedagogical approaches that enhance learning and employment.

This report indicates that relatively few programs are specifically designed with the developmental and learning needs of adolescent girls in mind. Rather, the evidence highlights that adolescent girls are often subsumed under programs for younger girls or adult women. The compendium of policies and programs also suggests that skill development and knowledge acquisition vary enormously by grade level, both within and across countries, due to variations in school quality. The report is one of the first to stress the need for more data on the growing non-formal education sector. While there has been a rapid rise in NGO-funded non-formal schools, there are no data on enrollments or learning outcomes for those participating in the non-formal sector and no data on the social and economic returns for girls who enroll in these programs.

\section{Key Findings}

New Lessons has served to debunk several widely-held myths on the schooling experiences of adolescent girls.

Myth: The majority of adolescent girls in poor countries are not in school. Facts: In most countries, even the poorest, the majority of younger adolescent girls are attending school, typically formal primary school. Later in adolescence, fewer girls attend formal schools, but among adolescent students ages 15-19, more are likely to be found in secondary school than primary school, although there are notable exceptions (Figure 1). It should be noted that in the poorest countries, secondary school completion among girls is relatively rare.

Myth: Girls fall behind boys in school. Fact: With the exception of a few countries, younger adolescent girls who remain in school are less likely to be behind in terms of grade-for-age than boys.

Myth: Pregnancy and early marriage are leading causes of dropout among adolescent girls. Fact: While dropout rates rise with age and are often greater for girls than boys among older adolescents, girls are more likely to drop out for reasons other than pregnancy and early marriage; pregnancy and early marriage tend to occur shortly after dropout.

Myth: Young women with a formal primary education can be assumed to be functionally literate. Fact: The effectiveness of formal primary schools in teaching literacy varies enormously; girls with three to five years of schooling cannot necessarily be assumed to be literate. 
Myth: Out-of-school girls are unschooled and therefore uneducated. Facts: Out-of-school adolescent girls represent a diversity of educational backgrounds with respect to formal schooling. Data on non-formal education are not currently collected; the number of out-of-school girls participating in non-formal education programs is unknown.

\section{Manifesto for girls' education}

Based on the evidence outlined in New Lessons, the authors put forth an educational manifesto for adolescent girls. In the manifesto three developmental and learning phases during adolescence are outlined and, within each, learning goals and preferred educational pathways for girls, including curricular building blocks, are identified (Box 1). The report provides strong evidence of a high return to girls from formal secondary school, and the lack of evidence of returns from non-formal alternatives underlies our preference for formal school at each phase of adolescent development. The authors assert that continuing education during adolescence is a necessary first step for girls if they are to overcome a history of disadvantage in paid employment and civic life.

\section{Proposed Actions}

To achieve the goals outlined in our educational manifesto for girls, the authors propose that governments, education ministries, donors, NGOs, and corporations incorporate the following actions in collaborative and innovate efforts to invest in a range of educational opportunities for adolescent girls:

Collect and compile data on non-formal education. A questionnaire module on non-formal education should be introduced into national household surveys and censuses to collect data on the extent and coverage of non-formal schooling, and its implementation should be tested on a pilot basis in several countries.

Build and maintain a global database for education programs for adolescent girls. The report's program and project compendium should become the platform for the development of a dynamic global database of education programs that serve adolescent girls. Its scope should be expanded in order to identify promising models appropriate to girls' educational needs in different settings. This database should be made available to donors, practitioners, and international agencies.

Expand opportunities for girls to attend secondary school. Governments should define basic education as education through lower secondary school, or to age 16. To accommodate the resulting influx of students, governments and the private sector should increase the number of formal and non-formal secondary school places in the educational system by extending existing primary school facilities and offering well-targeted subsidies to disadvantaged girls to attend either public or private secondary schools.

Support the non-formal education system. The non-formal education system must be well integrated with the formal system and be designed to help adolescent girls to achieve their educational and developmental needs. Non-formal schools must be upgraded, certified, and licensed,

\section{Box 1. An educational manifesto for adolescent girls}

\section{Early adolescence: Ages 10-12}

Where every girl should be: Formal primary school or accelerated complementary school

What every girl should be acquiring: Literacy, numeracy, critical thinking skills, basic health knowledge, knowledge about their communities and the world

\section{Middle adolescence: Ages 13-15}

Where every girl should be: Post-primary formal school or accelerated complementary school

What every girl should be acquiring: Reading and writing fluency for lifelong learning, critical thinking skills, fluency in an internationally spoken language, computer skills, proficiency in math/science, health and reproductive health knowledge, financial literacy, skills for social and civic participation, knowledge about social systems and local and global issues

Late adolescence: Ages 16-19

Where every girl should be: Formal secondary school or alternative education with a vocational or livelihoods focus

What every girl should be acquiring: Marketable skills, information-gathering skills and habits for lifelong learning, financial knowledge and skills

and pathways should be established from the non-formal to the formal sector, as well as from the formal to the non-formal sector. Baseline surveys should assess educational backgrounds, skills, and knowledge gaps of population subgroups who are potential beneficiaries, in order that educational systems can be designed to address existing needs.

Develop after-school tutoring and mentoring programs in both primary and secondary schools. These programs should support girls' education and development and enhance their chances of progressing to or succeeding in secondary school. They can provide one-on-one mentoring and ensure that after-school hours are dedicated to study and not to part-time jobs or family obligations. The programs can also provide supplementary training beyond the formal curriculum for the development of skills for social and civic participation-in the process teaching basic health, reproductive health, and financial literacy.

Produce curricula relevant to adolescent girls. Adolescent girls in the developing world need to acquire remunerative and marketable skills which are not taught at home, such as facility with computers, fluency in an internationally spoken language, financial skills, and knowledge of social systems. New methods to promote interactive and collaborative learning can help develop critical thinking and decisionmaking skills and instill a habit of lifelong learning -capacities that will equip girls for a rapidly changing world. 
Offer post-secondary vocational programs. The majority of girls who complete secondary school do not continue on to university. For girls going directly into the workforce, it is important to offer programs that support them in making a successful transition to remunerative work and household financial management. Such programs must be based on market assessments and provide relevant, flexible skills for employment and professional growth in an ever-changing global economy.

Provide training and ongoing incentives for women to enter and remain in teaching. Female teachers can reinforce the importance of education to girls, and many girls respond better to female teachers. The number of women who enter teaching is increasing, and teaching appears to be a viable, desirable profession for women who have completed secondary school.

Promote easy transitions between non-formal and formal schools. Complementary schools should be developed within the non-formal education system to help girls, many of them primary-school dropouts, continue on to formal secondary school. They should also offer younger adolescents the opportunity to reenter formal primary school.

Encourage and evaluate innovation. The curricula in both formal and non-formal schools attended by adolescents should be revamped to develop new approaches to education. Although many of the current approaches are unproven, some appear particularly promising. To test their effectiveness, research/program partnerships should invest in designing and implementing pilot projects to measure and assess their impact on girls over the short and medium term.

\section{Future Directions}

Even with a shortage of information on adolescent programs in the formal and non-formal sectors, New Lessons builds a case for rigorous efforts by governments and NGOs to improve the educational standards for adolescent girls. To continue the progress of the past 15 years, interested parties can collaborate to build on the successful programs discussed in the report.
Education for girls during adolescence alone cannot overcome the gender gap. Social forces that prevent the majority of girls from completing secondary education also manifest themselves in the workplace and in societal norms, making it hard for many girls to translate their educational gains into remunerative employment. Other complementary social efforts will be required to open previously closed pathways for girls. But if girls are not adequately educated during childhood and adolescence, they will not be in a position to seize new opportunities. These complementary efforts, well outlined in the Girls Count series, include a supportive legal environment that fully recognizes the equal rights of girls and women and enshrines those rights in law and practice.

Given the promising approaches identified in New Lessons, the authors suggest the implementation of pilot research to measure and assess the impact of these new educational strategies on girls' health and wellbeing. They focus particularly on supply-side strategies to ease transitions to secondary school, to enhance the learning environment for girls, and to address girls' developmental and learning needs more directly. Furthermore, they strongly recommend that impact evaluations become a routine and standardized practice in all education activities. They also recommend that evaluations go beyond the assessment of outcomes such as enrollment and grade attainment to assess the acquisition of knowledge and skills, particularly critical thinking and problemsolving skills, as well as longer-term outcomes such as work transitions, gender role attitudes, and measures of civic participation.

\section{References \& Resources}

Levine R., C.B. Lloyd, M. Greene, and C. Grown. 2008. Girls Count: A Global Investment \& Action Agenda. Reprint, 2009. Washington, D.C.: Center for Global Development.

Lloyd C.B. and J. Young. 2009. New Lessons: The Power of Educating Adolescent Girls. New York, N.Y.: Population Council.

United Nations. 2008. The Millennium Development Goals Report 2008. New York: United Nations.

\section{Donors}

Nike Foundation

United Nations Foundation

\section{Population Council}

The Population Council changes the way the world thinks about critical health and development issues. We seek to understand the causes and consequences of gender inequality and the disparities in opportunity that arise during adolescence. We provide the evidence for better on-theground programs and policies that ensure successful and productive transitions to adulthood in developing countries. www.popcouncil.org

() 2011 The Population Council, Inc

4 - Visit www.popcouncil.org/publications/serialsbriefs/TABriefs.asp for all briefs in the Promoting healthy, safe, and productive transitions to adulthood series. 